\title{
As atividades de produção oral no livro didático de língua inglesa sob a perspectiva das teorias de gêneros textuais e dos estudos do letramento
}

\author{
Raquel Santos Lombardi \\ Universidade Federal de Juiz de Fora \\ Marta Cristina da Silva \\ Universidade Federal de Juiz de Fora
}

\begin{abstract}
Resumo
Este trabalho tem por objetivo analisar como se desenvolve a produção oral em um livro didático de Inglês do $6^{\circ}$ ano aprovado pelo PNLD, sob a ótica dos gêneros textuais (abordagens sociodiscursivas e sociorretóricas) e dos novos estudos do letramento, avaliando sua adequação para o uso eficiente de gêneros orais.
\end{abstract}

Palavras Chave: Gêneros, letramento, produção oral.

\begin{abstract}
This paper analyzes how oral production is developed in an English textbook for the 6th grade approved by the "PNLD", from the perspectives of genre (socio-discursive and sociorhetorical approaches) and new literacy studies, evaluating its adequacy for the efficient use of oral genres.
\end{abstract}

Keywords: Genres, literacy, oral production.

\section{INTRODUÇÃO}

No âmbito do ensino de língua estrangeira, há muito se discutem as abordagens e metodologias para se trabalhar a oralidade em sala de aula. No Brasil, sabe-se que os Parâmetros Curriculares de Língua Estrangeira (PCN, 1998) orientaram a ênfase na leitura, por diversas razões, o que não deixou de ser alvo de embates, tanto do ponto de vista dos estudos teóricos quanto das práticas pedagógicas. Já no Programa Nacional do Livro Didático (PNLD) - 2011: Língua Estrangeira Moderna encontram-se critérios específicos para a avaliação dos livros didáticos referentes à compreensão e produção oral (p. 17 e 18). Nesse documento, defende-se o ensino integrado das quatro habilidades (ler, escrever, falar, ouvir) nas coleções, o que se manteve para a avaliação dos livros do Ensino Médio (PNLD 2012). De modo geral, tem havido um interesse crescente pelo ensino-aprendizagem das habilidades orais na educação básica, o que ainda demanda pesquisas mais aprofundadas. Nesse sentido, faz-se relevante investigar 
as práticas orais propostas nos livros didáticos, que não só medeiam as práticas pedagógicas dos professores como representam, muitas vezes, seu principal aporte teórico-metodológico.

Este trabalho, que faz um recorte de uma pesquisa maior, pretende analisar como as atividades de produção oral são desenvolvidas em um livro didático de inglês do $6^{\circ}$ ano do ensino fundamental, verificando se essas atividades estão adequadamente ancoradas na noção de gênero e se focalizam a língua em sua dimensão social. Além disso, observaremos se tais atividades são também adequadas para promover letramentos, dando condições aos aprendizes de lidarem com situações que apontem para suas práticas sociais.

Para tal, recorremos a uma pesquisa documental, em uma abordagem qualitativa, analisando as atividades de produção oral no livro didático selecionado sob a perspectiva das teorias de gêneros (abordagens sociodiscursivas e sociorretóricas) e dos estudos de letramento, em especial, o letramento em língua estrangeira. Tecemos também considerações sobre as dificuldades do processo de transposição didática. A maneira como as atividades analisadas ocorrem na prática de sala de aula não será observada, pois isso foge ao escopo deste trabalho, embora reconheçamos que a intervenção do professor sobre o material didático é de grande importância.

Esperamos contribuir na investigação de como os gêneros orais são abordados pelo livro didático de inglês e, ainda, fomentar a discussão sobre o conceito de letramento no contexto de ensino de língua inglesa.

\section{PRESSUPOSTOS TEÓRICOS}

\section{Gêneros textuais}

No cenário atual, a noção de gênero se configura como central para o ensino de língua. Isso não significa que práticas pedagógicas não orientadas pelos gêneros estejam fadadas ao fracasso, mas o grande volume de pesquisas nessa área comprova que se trata de um caminho produtivo. Essa noção favorece reflexões voltadas não apenas para tipos de textos próprios das esferas escolares e acadêmicas, mas também para diversos gêneros que circulam no mundo social, em diferentes situações de produção, dos gêneros literários aos do cotidiano.

Sendo assim, a definição de gênero se torna uma tarefa complexa, sendo objeto de correntes teóricas diversas, que nem sempre dialogam entre si. Neste trabalho, 
abordaremos o conceito de gênero com base em abordagens sociodiscursivas e sociorretóricas, centrando-nos na teoria bakhtiniana dos gêneros e na proposta de John Swales.

Segundo Bakhtin (1997[1952]), a utilização da língua está estreitamente relacionada com cada esfera de atividade humana e se realiza através de enunciados. Assim, "qualquer enunciado considerado isoladamente é, claro, individual, mas cada esfera de utilização da língua elabora seus tipos relativamente estáveis de enunciados, sendo isso que denominamos gêneros do discurso" (BAKHTIN, 1997[1952], p. 280).

De acordo com essa definição, portanto, em cada comunidade discursiva, é a partir dos gêneros que os textos se organizam. Em outras palavras, os gêneros são correlacionados às situações de interação dentro de uma dada esfera social como, por exemplo, a esfera cotidiana, escolar, religiosa, do trabalho, entre outras, como salienta Rodrigues (2005).

Entendendo que se utiliza a língua nas várias esferas de atuação humana com um dado objetivo, evidenciando uma finalidade para se chegar ao destinatário, associamos à perspectiva de Bakhtin o conceito de propósito comunicativo presente na proposta sociorretórica de John Swales. Esse autor, valendo-se de quatro perspectivas teóricas (folclore, estudos literários, linguística, mais especificamente, a linguística sistêmicofuncional de Halliday, e retórica), chega à seguinte definição de gênero:

\footnotetext{
Um gênero compreende uma classe de eventos comunicativos, cujos membros compartilham os mesmos propósitos comunicativos. Esses propósitos são reconhecidos pelos membros especialistas da comunidade discursiva de origem e, portanto, constituem o conjunto de razões para o gênero. Essas razões moldam a estrutura esquemática do discurso e influenciam e impõem limites à escolha de conteúdo e estilo. (SWALES, 1990, p. 58)
}

Assim, o conceito de propósito comunicativo, ou seja, a ideia de que os gêneros tem a função de realizar um objetivo ou vários objetivos, seria o principal critério na definição do gênero. Entretanto, esse conceito foi revisitado por Askehave e pelo próprio Swales, perdendo seu caráter principal na definição do gênero e passando a ser visto como parte de um conjunto de elementos, como apontam Hemais e BiasiRodrigues (2005). O propósito comunicativo continua integrando a definição, mas não como algo determinante e evidente, e sim como um elemento que pode ser incluído para se identificar um gênero, funcionando como um "critério privilegiado, em função do resultado da investigação sobre o gênero" (HEMAIS; BIASI-RODRIGUES, 2005, p. 119). 
Explicitada brevemente a noção de gênero que aqui adotamos e reconhecida a sua complexidade, passamos à questão do letramento, conceito que também fundamenta nossa análise.

\section{Letramento}

Os estudos sobre letramento, este entendido como prática social, evocando os "usos sociais da leitura e da escrita" (STREET, 1984), podem ser articulados à noção de gênero desenvolvida acima, na medida em que focalizam o uso da língua em geral na vida em sociedade e "tem insistido no caráter sociocultural e situado das práticas de letramento" (ROJO, 2009, p. 102).

Os letramentos, devido a sua natureza plural, apresentam-se como algo que vai além do domínio da leitura e da escrita como meras tecnologias autônomas. Em consonância com Street (1984, 2003) e Kleiman (1995), os letramentos estão ligados ao contexto social em que são praticados, variam no tempo e no espaço e envolvem, necessariamente, relações de poder.

\section{Letramento em língua estrangeira}

O conceito de letramento torna-se relevante no processo de ensino-aprendizagem de língua estrangeira, no caso o inglês, se pensarmos no papel dessa língua nos dias atuais. $\mathrm{O}$ inglês é frequentemente solicitado no meio acadêmico, profissional e, em certos casos, no meio social. Dessa forma, essa língua se apresenta como um fator que pode promover ou não a exclusão de um indivíduo, já que auxilia no desenvolvimento deste como cidadão, pois pode contribuir para a sua inserção na sociedade em diversas práticas sociais.

Seabra (2007) afirma que a concepção de letramento no ensino de língua estrangeira extrapola o texto escrito, pois o processo de construção de significados não se encerra nele ou na língua como código linguístico, mas se baseia na negociação de sentidos, os quais são interpretados e construídos socialmente.

Essa autora aponta para a pertinência de um letramento em língua estrangeira propriamente dita. Assim, leva em consideração as dimensões sociais da aprendizagem de língua inglesa, concebendo esse letramento como "algo que leva a uma consciência das diferenças culturais e do pensamento crítico a respeito dos acontecimentos, significados e do contexto social com os quais o aprendiz se depara" (SEABRA, 2007, p. 51). A autora defende a utilização de teorias de letramento, considerando que o 
letramento é "algo culturalmente construído e intimamente ligado às práticas socioculturais de uso da língua em uma dada sociedade e, portanto, de suma importância no ensino de uma LE e da cultura a ela relacionada" (SEABRA, 2007, p. $52)$.

O letramento é um forte aliado frente, até mesmo, à tarefa de socialização a ser experienciada pelos aprendizes. Eles poderão passar por situações em que terão que se socializar em outra língua, seja de forma escrita ou oral. Nesse sentido, o letramento, por "requerer a familiarização com novas práticas, crenças, valores, atitudes e formas de pensar de uma sociedade" (SEABRA, 2007, p.54) pode auxiliar o aprendiz a lidar com tal situação.

Essa socialização abarca, assim, a questão da oralidade. Notamos que o desenvolvimento de habilidades orais é uma necessidade crescente dos aprendizes. É frequente ouvirmos que um aprendiz tem como objetivo se fazer entender, comunicar-se na língua alvo. Todavia, as práticas de letramento relacionadas à produção oral ainda parecem carecer de uma investigação mais detalhada, a fim de fornecer subsídios para o desempenho e análise das competências orais.

\section{A questão da oralidade}

É perceptível, nos dias de hoje, uma espécie de supremacia da língua escrita em relação à língua falada. Parece fazer parte do senso comum que aquilo que é escrito é mais confiável e de maior valor. No que diz respeito à escola, podemos observar, também, uma supervalorização de práticas voltadas para a escrita em detrimento do trabalho real e eficaz com as habilidades orais.

Esse quadro decorre, certamente, da concepção de oralidade que permeia o ensino escolar. Schneuwly (2004) afirma que as representações usuais do oral giram em torno de três grupos. O primeiro deles nos revela o oral como algo material, considerando apenas o meio físico pelo qual se produz o oral. Em um segundo grupo, temos a percepção do oral como algo estritamente associado à espontaneidade. Nesse sentido, o oral seria o lugar da expressão pessoal, da opinião, e dos sentimentos, sem formulação prévia. Por fim, no terceiro grupo, o oral está ligado à norma, refletindo um trabalho que visa à expressão correta, com ideias coerentes e vocabulário adequado.

De acordo com esse autor, o oral espontâneo e o oral cotidiano não parecem constituir objetos de ensino, pois não são passíveis de intervenção sistemática, sendo aprendidos de forma natural. Dessa maneira, o oral a ser aprendido e sistematizado é o 
oral da escrita, que requer uma formulação anterior e que permite que se passe ao escrito, evidenciando apenas uma oralização da escrita.

Sendo assim, duas abordagens de ensino parecem aflorar no âmbito escolar. Uma delas centra-se na expressão de sentimentos próprios do aluno; na expressão de si. $\mathrm{O}$ autor considera que tal abordagem não define objetivos pedagógicos e didáticos precisos. Daí resulta o fato de a expressão de si não requerer, a princípio, que se leve em conta o contexto social que circunda tal expressão. Além disso, podemos dizer que aqui se aloca o pensamento arraigado de que o aluno já domina tal habilidade (falar de si), não sendo necessário que a escola lhe ensine.

Outra abordagem que pode ser percebida é o trabalho sistemático com habilidades orais com vistas a um falar culto e formal, visando a um ensino que forneça ao aluno condições de se expressar de forma correta frente ao público, ou em situações formais. Aqui, a dependência da escrita se amplia, já que as atividades, geralmente, culminam em textos escritos. Marcuschi (1997) afirma que tal abordagem, que evidencia uma oralização da escrita, provém de atividades que não se associam a uma discussão a respeito da fala propriamente dita; em função disso, tais atividades não seriam eficientes para o desenvolvimento da oralidade, funcionando, então, como pretextos, sistematizações de características da fala através do meio escrito.

Mesmo diante das limitações que perpassam o ensino do oral, não podemos deixar de reconhecer que "uma pedagogia do oral não estaria na contramão das ações educacionais, já que a fala pública é solicitada ao cidadão nas diversas situações do seu dia-a-dia” (MAGALHÃES, 2008, p. 139). Além desse fato, "o trabalho exclusivo com a escrita não promove um ensino eficiente e, consequentemente, uma compreensão global do que seja realmente a Linguagem" (MAGALHÃES, 2008, p. 140). Nesse sentido, a oralidade reivindica seu lugar dentro do processo de ensino-aprendizagem, apesar de suas especificidades e sua transposição didática ainda requererem algumas reflexões. É o que veremos a seguir.

\section{A transposição didática}

Frente a um conhecimento científico, a um conjunto de objetos teóricos, faz-se necessário pensar como se dará a transposição para o ensino, levando-se em conta o material que viabilizará esse processo: o livro didático.

Machado e Cristovão (2006) mostram-nos que o termo transposição didática não deve ser entendido, apenas, como a simples e pura aplicação de uma determinada teoria 
ao ensino, já que esse processo compreende o conjunto de transformações que um dado conjunto de conhecimentos sofre para que estes possam, então, ser ensinados; aspecto que envolve deslocamentos, transformações e, até mesmo, rupturas.

Essas autoras consideram que há três níveis básicos relacionados às transformações sofridas por uma teoria científica. No primeiro, o conhecimento científico sofre um processo inicial de transformação, a fim de passar ao conhecimento a ser ensinado. Este, em um segundo nível, transforma-se no conhecimento efetivamente ensinado, o qual, por fim, ainda se constituirá em um conhecimento efetivamente aprendido.

No que diz respeito à transposição didática da noção de gênero, as autoras salientam que, mesmo em documentos oficias de ensino, como os PCN, podemos evidenciar apenas o primeiro nível de transposição mencionado acima. Nesse nível, os objetos a serem escolhidos para serem ensinados passam por um controle social exercido, certamente, pelas autoridades de ensino.

Ao abordar a questão da transposição didática, é preciso considerar documentos e programas oficiais de ensino como os PCN e o PNLD. No contexto brasileiro, como as recomendações e prescrições desses documentos e o trabalho do professor em sala de aula são mediados, muitas vezes, pelo livro didático, podemos afirmar que o PNLD pode auxiliar no processo de transposição didática, uma vez que, através de sua aprovação ou não de um material, determina o que poderá servir de apoio para que se desenvolva um ensino que esteja de acordo com os objetivos do ensino de línguas, tais como elaborados nos PCN. Dessa forma, os critérios do PNLD podem guiar a transposição de um dado conhecimento científico a um conhecimento a ser ensinado. Vale lembrar, entretanto, que o professor pode, na prática didática, alterar a proposta do livro didático, aperfeiçoando-a ou adequando-a a seu grupo de alunos. Pelas limitações deste trabalho, verificaremos como se dá a transposição apenas na perspectiva do livro didático.

\section{METODOLOGIA}

Com o intuito de analisar as atividades de produção oral em um livro didático de língua inglesa com base nas questões teóricas abordadas, recorreremos a uma pesquisa documental de base qualitativa. Em linhas gerais, esse paradigma permite a investigação de determinada problemática não em sua interação imediata, mas de forma indireta, por 
meio do estudo dos documentos que são produzidos pelo homem e por isso revelam o seu modo de ser, viver e compreender um fato social.

\section{Apresentação do material de ensino}

Selecionamos o volume do $6^{\circ}$ ano do ensino fundamental da coleção de livros didáticos Links - English for Teens, de Amadeu Onofre da Cunha Coutinho Marques e Denise Machado dos Santos, da Editora Ática. Essa coleção foi aprovada pelo PNLD 2011, de acordo com os critérios observados pelo programa. Analisaremos duas unidades do referido material, as unidades 5 e 9, focalizando as atividades de produção oral.

Esse volume possui 10 unidades temáticas, divididas em várias seções: Let's Read, Let's Listen, Let's Speak, Grammar in Action, Grammar Notes, Words in Action, Let's Write, Let's Play e Let's Stop and think.

Voltaremos nossa atenção para as seções Let's Speak, na qual se apresentam as atividades de produção oral, com vistas ao desenvolvimento de estratégias de speaking; Let's Play, onde temos jogos que possibilitam a prática do conteúdo até então trabalhado; e Let's Stop and think, na qual se pode promover a reflexão de uma dada questão sociocultural.

\section{Análise do material de ensino}

Começaremos nossa análise com a unidade 5, People at work. Vale lembrar que utilizamos somente o que está expresso no livro didático, não considerando o desenvolvimento real das atividades em sala de aula, aspecto que pode alterar a execução de uma tarefa, pois a prática do professor pode modificar a abordagem feita pelo livro.

Temos, então, a seção Let's Speak! Nela, deparamo-nos com a seguinte cena: 


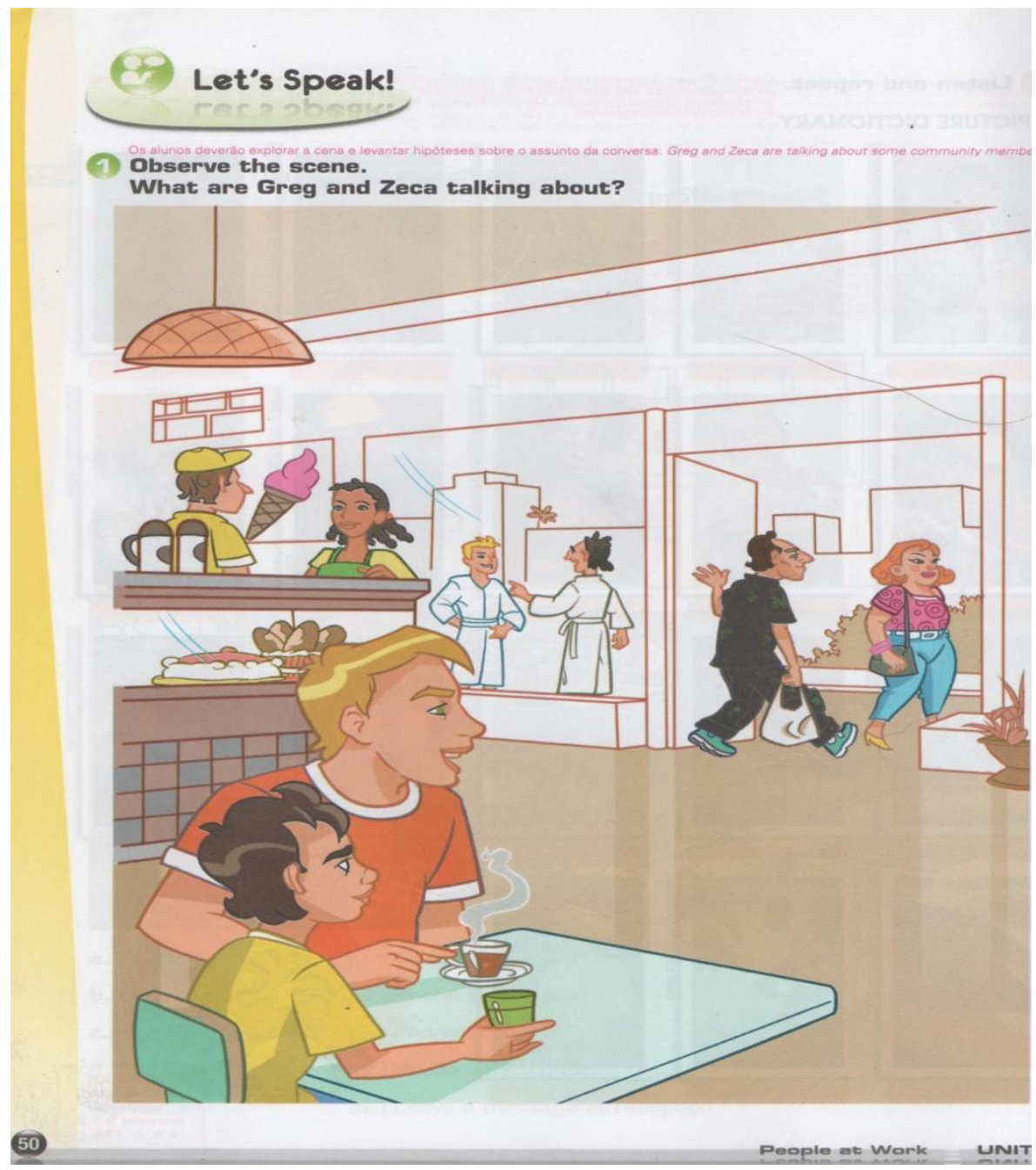


Conn o ivio fechado, as alunos deveráo ouvir o diálogo entre Greg e Zeca uma livro $\theta$ ouvir a gravaçáo novamente ennuanto fazem uma leitura silenciosa. Chame a atençáo para o uso das expressóes Ah, okay ("Ah, está bem"); Really? ("E

Greg: Is he a soldier? mesmo?" ") Of coursel ("Claro!"). Depois, peça que formem duplas para ler c

Zeca: No. That's Carlinhos Tinta. He's a painter.

Greg: Ah, okay. What about her? Is she an actress?

Zeca: Oh no. That's Marianne. She's a hair stylist.

Greg: Really? And those two guys? Are they sailors?

Zeca: No, they're capoeira dancers.

Greg: Of course!

(3) Your turn!

Talk to a friend about these people.

Os alunos deveráo criar dialogos semelhantes ao do exercicio anterior com base nas fotos e nas profissóes mencionadas a segur.

Conversation 1 Aluno 1: Is he a model? / Aluno 2: No. That's Felipe Massa. He's a Formula 1 driver. / Aluno 1: Ah, okay. What about her? Is she aprincess? / Aluno 2: Ohno. That's Keira Knightley. Shes's an actress. / Aluno 1: Really? And those two guss? Are they wizards? /
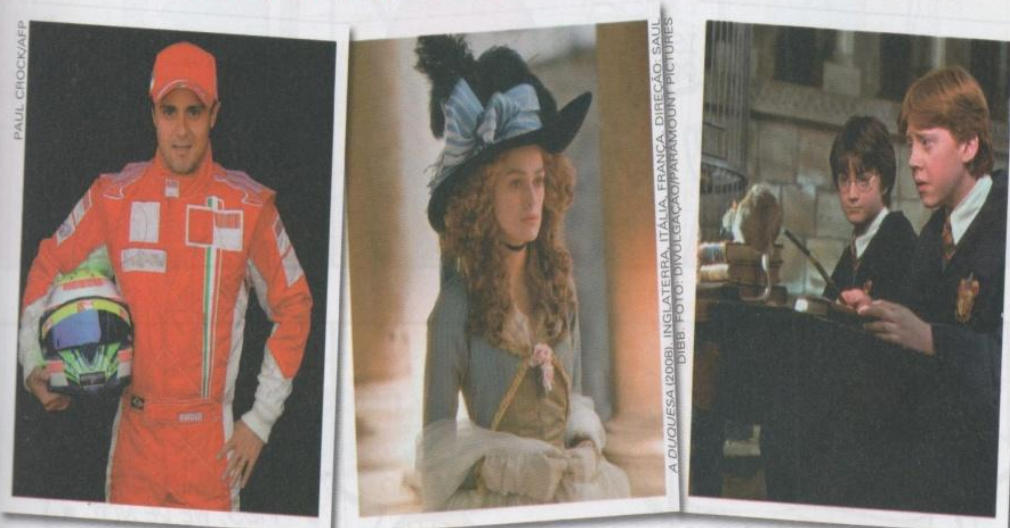

Question: model

Question: princess

Question: wizards

Answer: Formula 1 driver

Answer: actress

Answer: actors

Conversation Aluno 1: is he a model'? / Aluno 2: No. That's Kake. He's a soccer plaver / Aluno 1: Ah. okav. What about her? Is she a

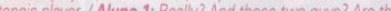
cowbovs? / Aluno 2: No, they are singers. / Aluno 1: Of courss

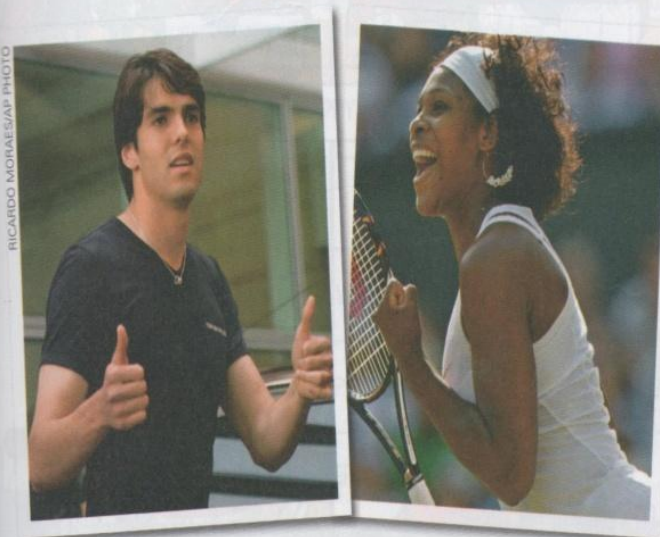

Question: model Answer: soccer player
Question: doctor Answer: tennis player

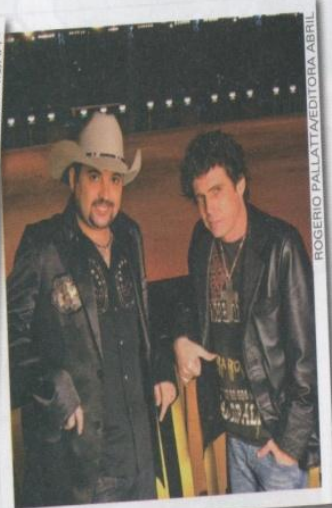

Question: cowboys Answer: singers 
Primeiramente, os alunos são incitados a descobrir o assunto da conversa. Logo após, no exercício 2, há um diálogo que deverá ser ouvido e depois lido silenciosamente enquanto se prossegue com a atividade de escuta, para que os alunos possam identificar as profissões ali mencionadas - o vocabulário dessa unidade gira em torno das profissões. As instruções sugerem que o professor chame a atenção para o uso de expressões de feedback, como really?, of course, ah, okay e outras, segundo o manual do professor. Por fim, na atividade 3, Your turn!, os alunos tem que criar diálogos semelhantes ao ouvido anteriormente com base nas figuras e profissões disponibilizadas.

Essa seção parece seguir um padrão regular ao longo do livro, organizando-se em atividades em que há um diálogo escrito que os alunos ouvem e dramatizam em duplas, ou ao qual recorrem como modelo para executar outra tarefa, como parte da atividade Your turn! Esse fato nos deixa entrever a dependência que o oral possui em relação à escrita, dando origem a uma oralização da escrita, nos termos de Marcuschi (1997) e Schneuwly (2004), já que a reflexão sobre a modalidade falada da língua se fundamenta em um texto escrito, partindo dele para se promover o oral.

As atividades 2 e 3 da seção Let's Speak! não evidenciam claramente um propósito comunicativo, fato que aproxima o diálogo ali presente a uma tarefa que tem como finalidade a prática do vocabulário em questão nessa unidade: as profissões. No entanto, não podemos deixar de observar que um trabalho sistemático com as profissões é necessário, pois, no futuro, esse vocabulário poderá ser exigido em uma situação social da vida do aluno. Esse aspecto deixa uma abertura, ainda que de forma muito tênue, para que se promova o letramento desse aluno, trabalhando-se de maneira a relacionar o vocabulário em estudo aos usos sociais da língua.

Vemos, então, que a noção de gênero embasa, de forma incipiente, as atividades de produção oral observadas nessa seção, pois há, de certa maneira, uma forma de uso da língua, relacionada a esferas de atividade humana (BAKHTIN,1997[1952]), a saber, o diálogo. Entretanto, não há espaço para uma conversação fora da estrutura de um diálogo fabricado para fins didáticos. O primeiro diálogo serve de modelo para o proposto no exercício 3 (talk to a friend about these people). Sendo assim, como observou Magalhães (2008), a finalidade está voltada para o conteúdo em foco, no caso, as profissões, não se relacionando à especificidade da língua falada, salvo pelo uso das expressões de feedback mencionadas acima. Além disso, ainda que o diálogo seja um 
gênero importante para os alunos, faz-se necessário o trabalho com outros gêneros orais que permeiam suas práticas sociais.

Na seção Let's Play! (anexo 3), temos o jogo da forca, como vemos na figura abaixo. Essa proposta de atividade configura um estímulo de uso da língua inglesa em uma esfera real de comunicação. Não se espera um "perfeito" desempenho oral, já que os alunos se encontram no $6^{\circ}$ ano; no entanto, pode-se, por exemplo, praticar o alfabeto em inglês de forma menos artificial.

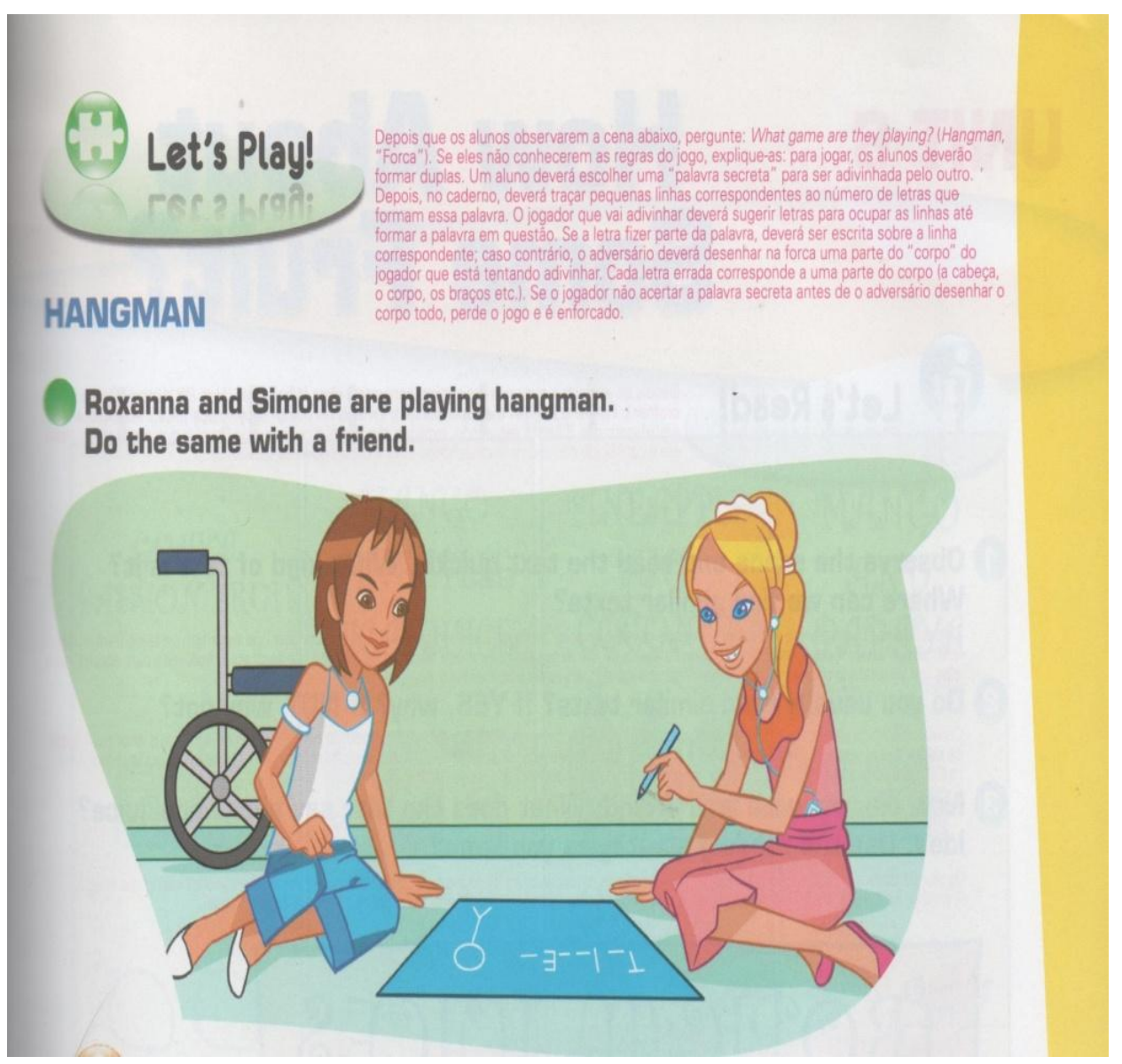

Para finalizar a unidade, temos Let's Stop and Think! 


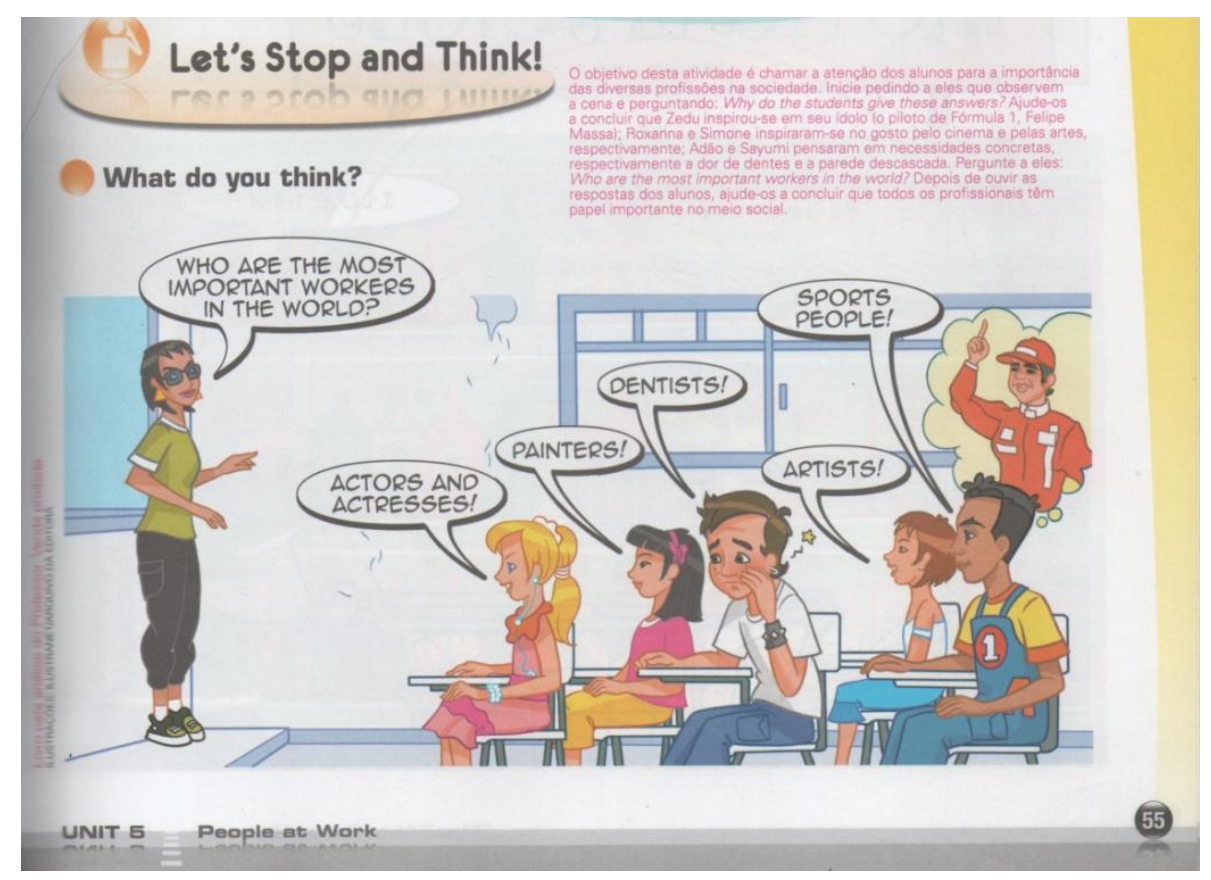

Objetiva-se, aqui, chamar a atenção para a importância das diversas profissões na sociedade. Encorajada devidamente, essa discussão poderia ser produtiva. A produção oral, guiada de forma a não se apoiar demais nas concepções usuais do oral, oscilando entre uma expressão resultante da espontaneidade, sem objetivos específicos, e a expressão oral vista como norma, na busca de um falar correto e elevado (SCHNEUWLY, 2004), poderia ocorrer de maneira bastante proveitosa. Ainda que os alunos se apoiassem na língua materna, o professor teria como estimular a sua produção oral em inglês, desde que isso não se resumisse ao padrão pergunta-resposta. O PNLD se refere a essa seção do livro como algo positivo, na qual "os alunos poderão refletir sobre diversidade, cidadania e consciência crítica" (PNLD 2011: Língua Estrangeira Moderna, 2010, p. 44).

Passaremos, agora, à unidade de número 9, Brazil is much more than that!. Na seção Let's Speak!, a proposta de produção oral ainda se restringe à escuta e dramatização de um diálogo. Com base em um diálogo a ser lido, ouvido e trabalhado pelo professor, com foco na estrutura “What's it like?” e na explicação dos significados de alguns adjetivos com nice, cool, lovely presentes no exercício 1, os alunos devem substituir as estruturas grifadas por outras que descrevam a sua cidade natal no exercício 3. O exercício 2, se organiza de forma mais estrutural, pedindo que os alunos formulem perguntas para as respostas fornecidas, como observamos a seguir: 


\section{Let's Speak!}

Depois de lerem os diálogos e observarem o uso da estrutura What's it like?, os alunos deverá́

tor a a hananin

desses adjetivos (eles dáo mais esclarecimentos sobre a descriçáo iniciada como uso de great.

(1) Read and listen.
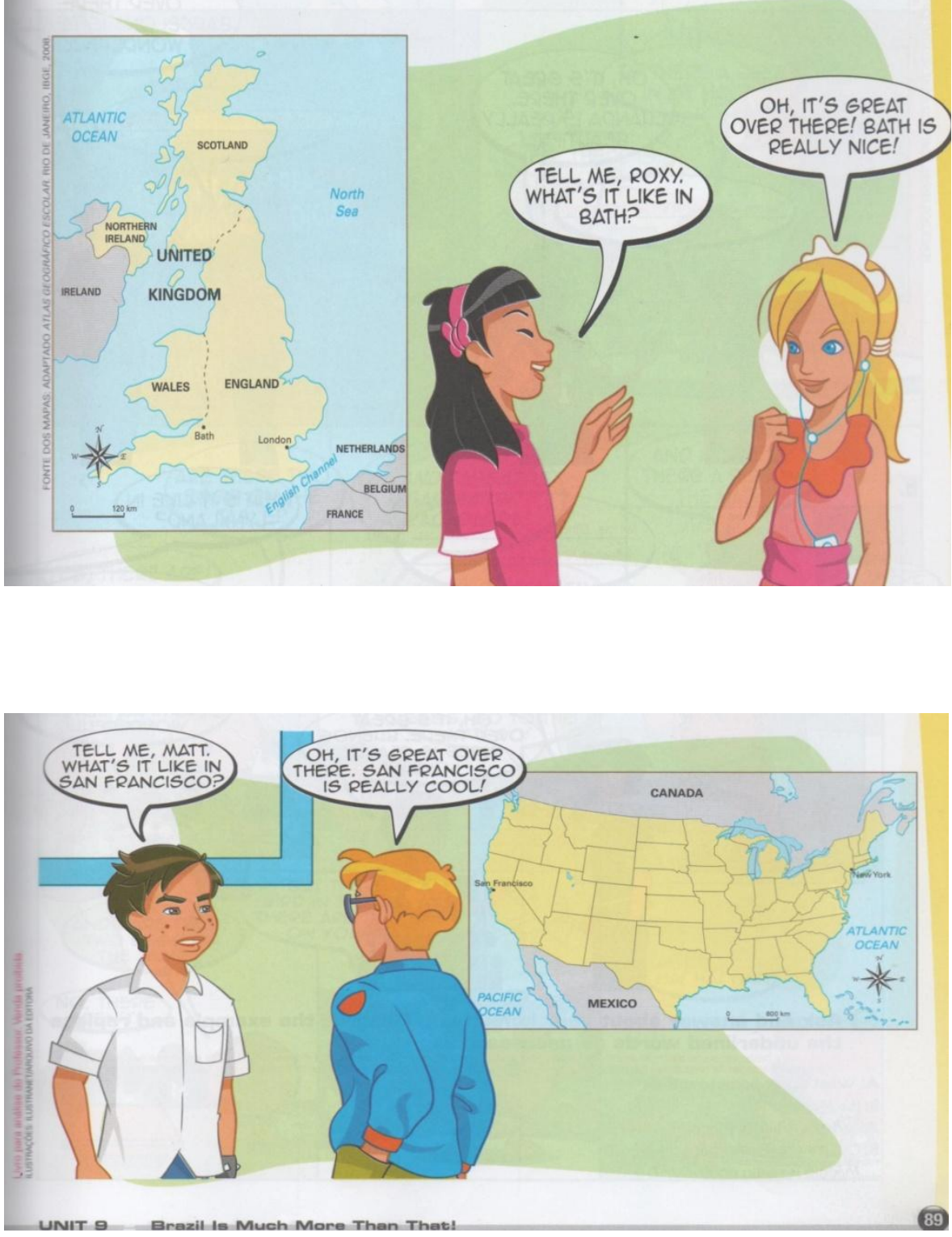


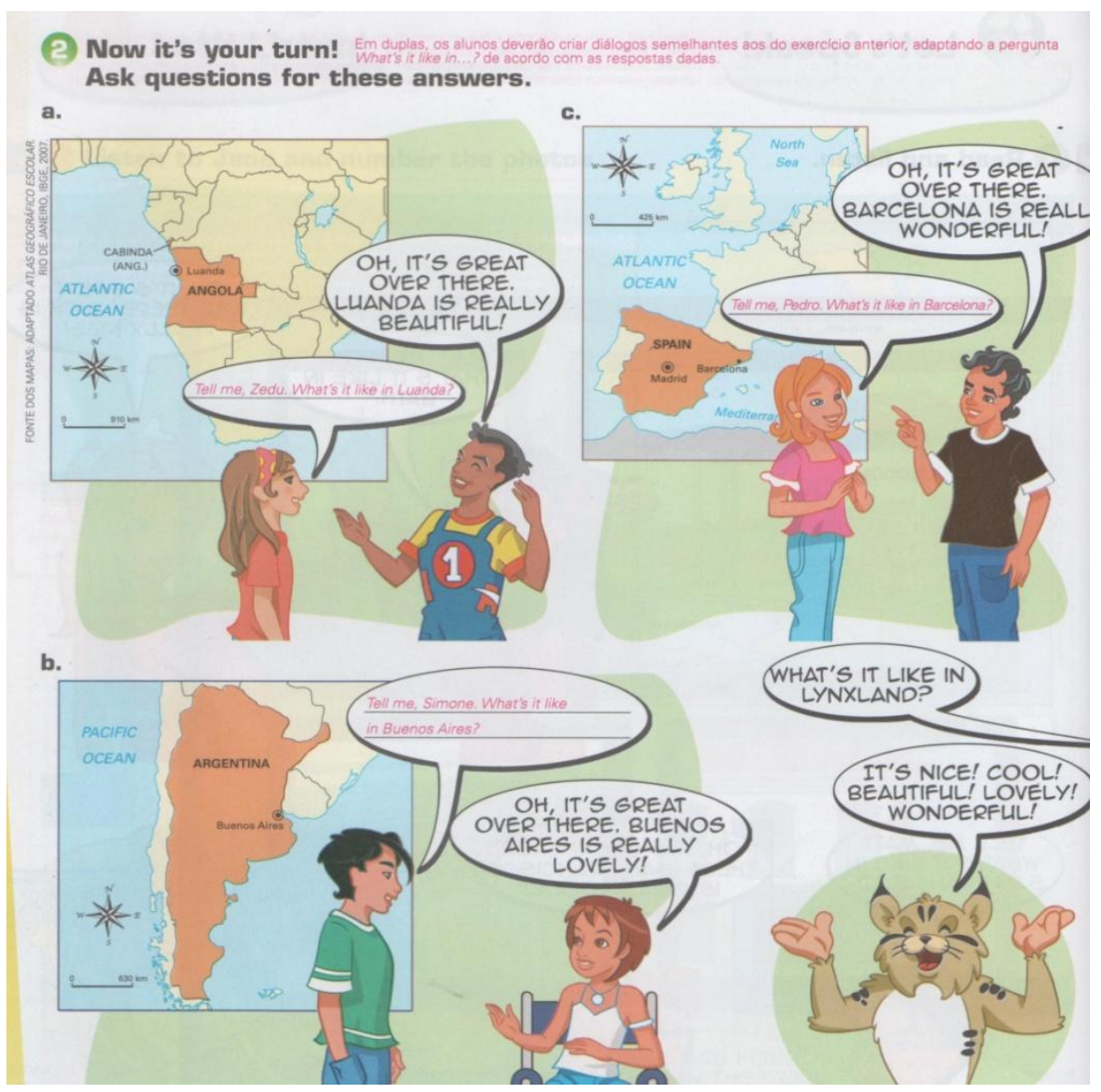

3 Ask and answer about your hometown. Observe the example and replace the underlined words as necessary.

Em duplas a baseando-se no exemplo abaixo, os alunos deveráo criar perguntas e respostas sobre a cidade natal de cada um. As palavras sublinhadies A: What's your hometown?

B: It's Maceió.

A: What's it like in Maceió?

B: Oh, it's great over here.

Maceió is really cool!

90

Brazil Is Much More Than That! = UNIT 9

Esse tipo de atividade que, de acordo com o manual do professor, fundamenta-se na estratégia de produção oral "expandindo respostas", não se articula adequadamente com a noção de gênero. O gênero diálogo não é trabalhado em termos de sua dimensão social. O livro didático, aqui, não propicia ao professor trabalhar com práticas de letramento oral. Além disso, os exercícios recorrem à modalidade escrita da língua, utilizando-se dela como uma espécie de pretexto para o trabalho com a oralidade. Temos, novamente, a questão da oralização da escrita. Nessas atividades não podemos evidenciar um propósito comunicativo efetivamente definido e real.

Em Let's Play!, a oportunidade de se recorrer ao uso da língua em um contexto menos monitorado é positiva. Vejamos a figura que se segue: 


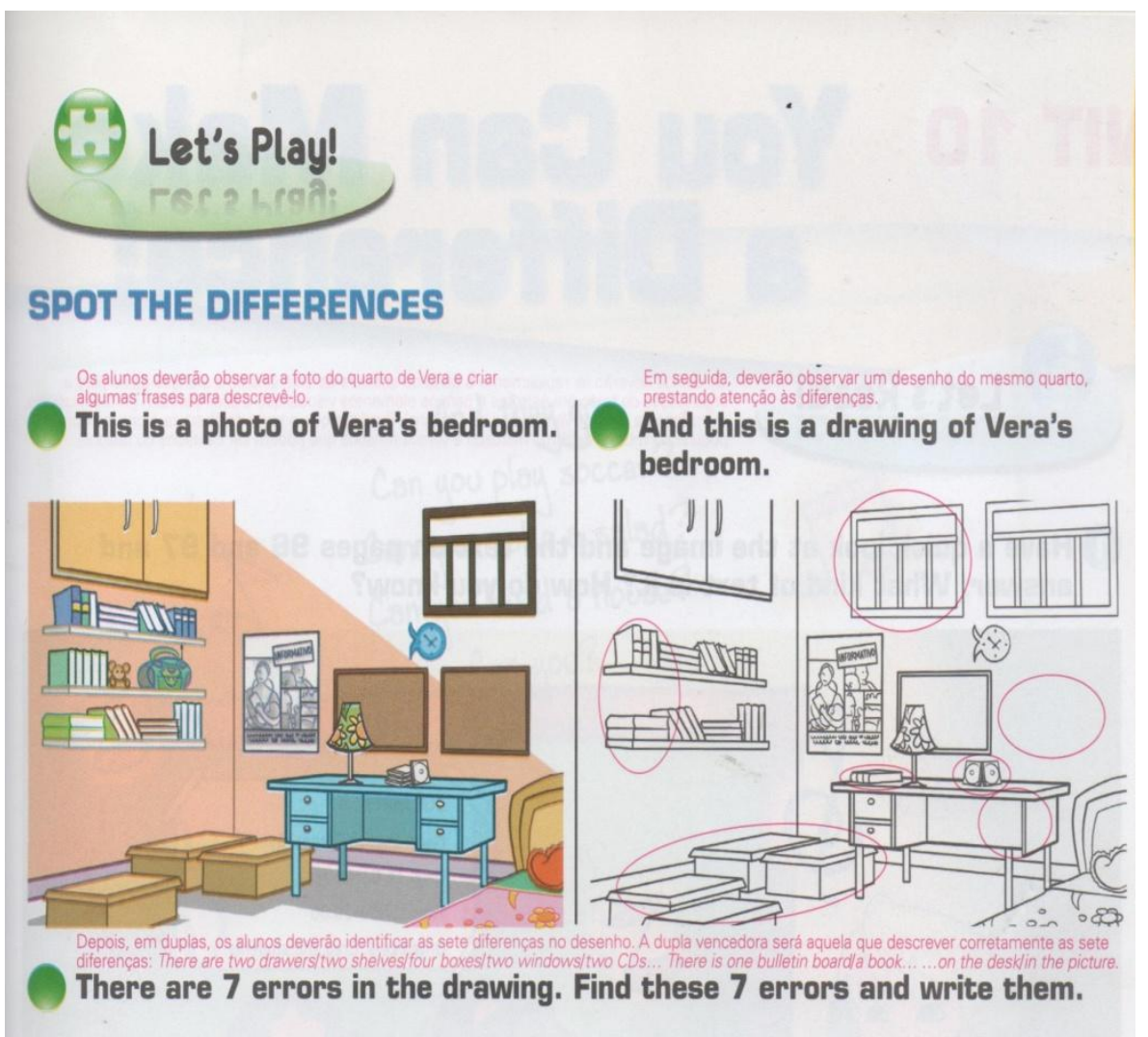

O jogo selecionado possibilita praticar estruturas gramaticais e vocabulário aprendidos na unidade e parece que esse é o foco. Apesar de ser um trabalho em duplas, que prevê interação, não há orientações para um trabalho oral.

Na seção Let's Stop and Think!, há instruções para que o professor incentive a reflexão sobre certos estereótipos que reduzem o Brasil a uns poucos aspectos de sua riqueza e diversidade, apontando para o fato de nosso país ser mais do que apenas futebol, carnaval e matas. Vejamos a figura a seguir: 


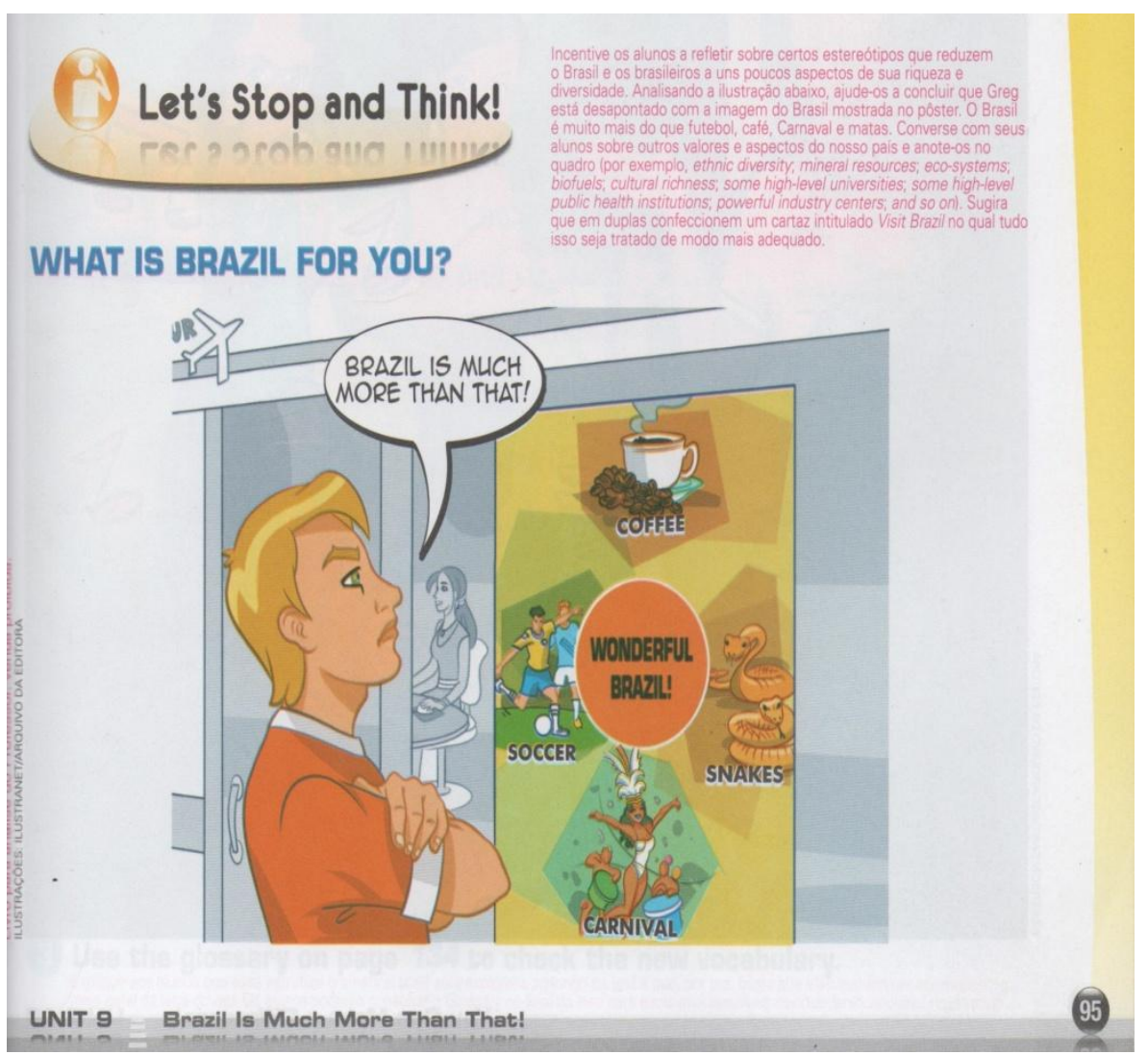

A proposta de produção oral apresenta-se como algo enriquecedor. Foi utilizada a conversa para se desenvolver a atividade, no entanto, tal conversa deveria preparar os alunos para compreenderem como é o gênero cartaz, uma vez que terão que confeccionar um exemplar. O que vemos é que isso não é explorado.

Diante do que observamos, podemos afirmar que as atividades propostas para se efetuar a produção oral ainda se encontram impregnadas pelo uso da escrita, apresentando-nos apenas uma oralização da escrita, evidenciada pelos exercícios que envolvem instruções do tipo "talk to a friend", embasadas em diálogos escritos previamente fornecidos. Além disso, parece se privilegiar o diálogo, em detrimento do trabalho com outros gêneros orais. Mesmo no diálogo, não é sugerida uma abordagem de elementos socioculturais, e não se identificam propósitos comunicativos facilmente. Nesse sentido, o livro apresenta propostas interessantes, mas que demandariam a intervenção do professor para seu êxito efetivo. Há igualmente atividades que parecem não promover os letramentos, pois não há uma maior aproximação das práticas letradas de que os alunos participam em sua vida real. 


\section{CONSIDERAÇÕES FINAIS}

Diante do exposto, notamos que a noção de gênero está presente, de certa maneira, no processo de ensino da oralidade no livro didático analisado. Como vimos, entretanto, falta uma maior diversidade de gêneros orais, e a abordagem carece de propósitos mais definidos e de um ensino mais sistemático voltado ao uso.

No que concerne ao desenvolvimento de letramentos, observamos que algumas poucas atividades se apresentaram como oportunidades para se promover o letramento do aluno, pois apontavam para possíveis práticas fora do contexto escolar, mesmo que de forma ainda pouco aprofundada, como vimos no caso do trabalho com as profissões. Apenas a análise da coleção como um todo pode confirmar se isso é um padrão.

As atividades de produção oral analisadas se configuraram como uma oralização da escrita. Em muitos momentos, a dependência do texto escrito foi forte e indispensável para a realização da tarefa proposta. Nesse sentido, não houve uma reflexão sobre os aspectos estritamente ligados à fala, ao gênero oral em si, pois o foco pareceu recair sobre o estudo de um determinado conteúdo a ser ensinado.

De todo modo, vimos que o livro didático pode, sim, ser um instrumento importante para se efetuar um trabalho de produção oral. Algumas atividades poderiam ser expandidas pelo professor, feitas as devidas adequações. O fato é que a produção oral não pode mais ser negligenciada no contexto da escola. Para isso é preciso que o professor, para além das avaliações oficiais, seja capaz de fazer sua própria avaliação, bem informado teoricamente, reivindicando livros didáticos cada vez melhores, que considerem as necessidades reais de uso da língua no mundo contemporâneo.

\section{REFERÊNCIAS}

Bakhtin, M. (1952/1997). Estética da Criação Verbal. São Paulo: Martins Fontes.

Brasil.(2010). Programa Nacional do Livro Didático do Ensino Fundamental. Secretaria da Educação Básica. Brasília: MEC.

Hemais, B. \& Biasi-Rodrigues, B.(2005). A proposta sócio-retórica de John M. Swales para o estudo de gêneros textuais. In Meurer, J. L., Bonini, A. \& Motta-Roth, D. (orgs) Gêneros: teorias, métodos, debates 108-129. São Paulo: Parábola Editorial.

Kleiman, A. (Org.) (1995). Os significados do letramento: uma nova perspectiva sobre a prática social da escrita. Campinas,SP: Mercado de Letras. 
Machado, A. R \& Cristovão, V. L. L. (2006). A Construção de modelos didáticos de gêneros: aportes e questionamentos para o ensino de gêneros. Linguagem em (Dis)curso - LemD, 6 (3), 547-573.

Magalhaes, T. G. (2008). Por uma pedagogia do oral. Signum: Estud. Ling., 11 (2), 137153.

Marcuschi, L. A. (1997). Concepção de língua falada nos manuais de português de $1^{\circ} \mathrm{e}$ $2^{\circ}$ graus: uma visão crítica. Trabalhos em Linguística Aplicada, 30, 39-79.

Brasil. (1998). Parâmetros curriculares nacionais. Terceiro e quarto ciclos do ensino fundamental - Língua estrangeira. Brasília: MEC/SEF.

Rodrigues, R. H. (2005). Os gêneros do discurso na perspectiva dialógica da linguagem : a abordagem de Bakhtin. In Meurer, J. L., Bonini, A. \& Motta-roth, D. (orgs) Gêneros: teorias, métodos, debates 152-183. São Paulo: Parábola Editorial.

Rojo, R. (2009). Letramentos múltiplos, escola e inclusão social. São Paulo: Parábola.

Schneuwly, B. (2004). Palavra e ficcionalização: um caminho para o ensino da linguagem oral. In Schneuwly, B. et al. Gêneros orais e escritos na escola 109-124. Trad. e org. Roxane Rojo e Glaís Sales Cordeiro. Campinas, SP: Mercado de Letras.

Seabra, D. M. (2007). A sócio-construção da leitura em língua estrangeira sob a perspectiva dos Novos Estudos do Letramento. Dissertação de mestrado, UNICAMPCampinas, SP.

Street, B. (1984). Literacy in Theory and Practice. Cambridge: Cambridge UP.

Street, B. (2003).What's "new" in New Literacy Studies? Critical approaches to literacy in theory and practice. Current Issues in Comparative Education, 5 (2), 77-91.

Swales, J. M. (1990). Genre analysis: English in academic and research settings. Cambridge: Cambridge UP.

\section{AS AUTORAS}

Raquel Santos Lombardi possui graduação em Letras (Português/ Inglês) pela Universidade Federal de Juiz de Fora (2007/2009), bacharelado em Letras: Ênfase em Tradução-Inglês pela Universidade Federal de Juiz de Fora (2009). Atualmente é mestranda no Programa de Pós-Graduação em Linguística da Universidade Federal de Juiz de Fora. Principais áreas de interesse: ensino de línguas; gêneros textuais (teorias e transposição didática); livro didático e letramentos.

E-mail: raquellombardi@yahoo.com.br

Marta Cristina da Silva é Doutora em Letras/Estudos Linguísticos pela Universidade Federal Fluminense. Atualmente é Professora Associada do Departamento de Letras Estrangeiras Modernas da Universidade Federal de Juiz de Fora, atuando na área de Língua Inglesa na graduação e na linha de pesquisa Linguística e Ensino de Língua no 
Programa de Pós-Graduação em Linguística. Principais áreas de interesse: gêneros textuais (teorias e transposição didática); livro didático; avaliação; letramentos.

E-mail: martacris.silva@gmail.com 